\title{
Emotion Regulation in Families of Children with Behavior Problems versus Nonclinical Comparisons
}

\author{
Lauren Borduin Quetsch
}

Follow this and additional works at: https://researchrepository.wvu.edu/etd

\section{Recommended Citation}

Quetsch, Lauren Borduin, "Emotion Regulation in Families of Children with Behavior Problems versus Nonclinical Comparisons" (2015). Graduate Theses, Dissertations, and Problem Reports. 6462.

https://researchrepository.wvu.edu/etd/6462

This Thesis is protected by copyright and/or related rights. It has been brought to you by the The Research Repository @ WVU with permission from the rights-holder(s). You are free to use this Thesis in any way that is permitted by the copyright and related rights legislation that applies to your use. For other uses you must obtain permission from the rights-holder(s) directly, unless additional rights are indicated by a Creative Commons license in the record and/ or on the work itself. This Thesis has been accepted for inclusion in WVU Graduate Theses, Dissertations, and Problem Reports collection by an authorized administrator of The Research Repository @ WVU. For more information, please contact researchrepository@mail.wvu.edu. 
Emotion Regulation in Families of Children with Behavior Problems versus Nonclinical Comparisons

Lauren Borduin Quetsch

Thesis submitted

to the Eberly College of Arts and Sciences

at West Virginia University

in partial fulfillment of the requirements for the degree of

Master of Science in

Psychology

Cheryl B. McNeil, Ph.D., Chair

Elisa Krackow, Ph.D.

Amy Gentzler, Ph.D.

Department of Psychology

Morgantown, West Virginia

2015

Keywords: emotion regulation, externalizing behavior problems, parent training Copyright 2015 Lauren Borduin Quetsch 


\begin{abstract}
Emotion Regulation in Families of Children with Behavior Problems versus Nonclinical Comparisons
\end{abstract}

\title{
Lauren Borduin Quetsch
}

The following study explored the relationship between emotion regulation in children with and without externalizing behavior problems and their caregivers. The study examined emotion regulation in both clinical and comparison samples. The main research question for the study was determining if there was a link between parent and child emotion regulation in both clinical and comparison samples. Sixty families were collected from two rural populations in the United States. Families referred for parent training with children ages 2 through 8 were recruited for a clinical sample $(n=34)$ along with a nonclinical comparison group $(n=26)$. A blocking design was used. The sample was largely Caucasian $(73.3 \%)$, boys $(71.7 \%)$, aged 4.62 years. Parents completed measures related to child behaviors, parenting stress, and child and parent emotion regulation at a single time point. Family behaviors were also coded during structured behavioral observations. Analyses indicated higher rates of problem behaviors in the clinical group, higher rates of parenting stress, higher levels of parental emotion dysregulation, and higher levels of child emotion dysregulation. Parents of children in the clinical sample also used more negative verbalizations with their children. Parent emotion regulation was found to be correlated with child emotion regulation, parenting stress, child behavior problems, and parental use of negative speech toward their child during play situations. Findings from this research indicate a need to target and measure outcomes for emotion regulation in both parents and their children when working with families who are referred for treatment of child behavior problems. 


\section{TABLE OF CONTENTS}

Title Page..........................................................

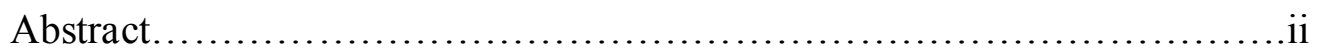

Table of Contents..................................................ii

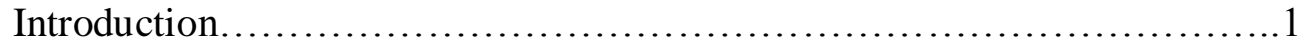

Method...............................................................

Participants.....................................................

Measures.......................................................4

Family Characteristics........................................4

Child Behavior Checklist (CBCL) .............................5

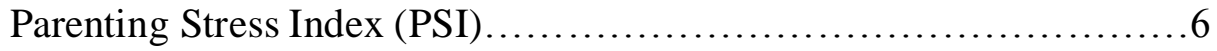

Difficulties in Emotion Regulation Scale (DERS) ..................6

Emotion Regulation Checklist (ERC)..........................

Dyadic Parent-Child Interaction Coding System (DPICS) .............8

Procedure........................................................ 9

Results........................................................ 10

Preliminary Analyses............................................ 10

Parental Emotion Dysregulation...................................11

Child Emotion Regulation.....................................11

Relationship of Parental and Child Emotion Regulation..................11

Child Abuse Sample...............................................14

Discussion....................................................... 15

Limitations................................................. 20

Future Directions/ Concluding Remarks............................22

References..................................................24

Tables......................................................... 33 
Emotion Regulation in Families of Children with Behavior Problems versus Nonclinical

Comparisons

Emotion regulation, or the ability to organize and control states of affective arousal, is an essential piece in adaptive psychological development (Thompson, 1994). The inability to properly regulate emotions is a feature of the majority of psychological disorders (American Psychiatric Association, 1994; Gross \& Levenson, 1997). While initial self-regulation attempts in infancy may be unsuccessful, children begin to learn and acquire emotion regulation skills through interactions with their parents (Thompson, 1994). Positive parenting (e.g., support, warmth) is believed to improve internalization of adaptive child emotion regulation strategies (Cole, Dennis, Smith-Simon, \& Cohen, 2008). In particular, skills such as accurately identifying and labeling emotions, methods for coping with frustration or distress, and guidelines for acceptable emotional expression in society can be passed down intergenerationally (Calkins, 1994). Over time, environmental factors such as family interactions significantly shape and contribute to the child's emotion regulation abilities.It is widely accepted that there is a connection between parent interactions with their children and their children's ability to regulate their emotions (see Wallace, Quetsch, Robinson, Gentzler, \& McNeil, in press for a review). Parental and family influences on child emotion regulation have steadily gained interest in the research community in recent years (Morris, Silk, Steinberg, Myers, \& Robinson, 2007). For example, in a study by Fosco and Grych (2012), the effects of family environment on the child's emotion regulation were examined. The children displayed more positive emotion regulation when their parents demonstrated warmth and sensitivity to the child. Positive parenting behaviors by mothers also correlated strongly with child compliance (Calkins, Smith, Gill, \& Johnson,1998). On the other hand, children living in a more negative and conflictive household displayed more dysregulated emotionality (Fosco \& Grych, 2012). Calkins and colleagues 
(1998) found that parents' negative behavior was related to poor physiological regulation, less adaptive emotion regulation, and noncompliant behavior for the child.

The dysfunction of parental emotion regulation in families can lead to various social, behavioral, and emotional problems for children (Cummings, Keller, \& Davies, 2005). Unresponsive and dismissive parents have children with more behavior problems and fewer emotion regulation abilities (Ramsden \& Hubbard, 2002). For evidence of parental influence on appropriate expression of emotion-related behavior, Garner (1995) found that maternal positive expressiveness in the family was positively linked with a child's ability to produce self-soothing regulatory behavior. Moreover, mothers who reported having more expressed family sadness were more likely to have children with poorer quality self-soothing behavior (Garner, 1995). While these behaviors are not direct representations of emotion regulation, there is a strong link in research of the influence of parental modeling and teaching of child behaviors and emotionrelated strategies.

Few studies to date have focused on parental levels of emotion regulation in parents of children with clinically significant behavior problems. While some measurements such as stress levels can provide an indicator for emotional dysregulation (Fossum, Morch, Handegard, Drugli, \& Larsson, 2009), a more thorough investigation of parental and child emotion regulation is warranted. Gathering a clinical family sample to compare to a nonclinical family sample may find a missing piece linking parent and child emotions.

The current study investigated the relationship between parent and child emotion regulation in families of children with behavior problems and comparable nonclinical families. The purposes of this study are: (a) to determine if parents and their children with behavior problems have more difficulties with emotion regulation as compared to nonclinical families, (b) to evaluate whether there is a correlation between parental and child emotion regulation in both clinical and nonclinical families, and (c) to assess how parental and child emotion regulation in 
families is associated with observable behaviors in a lab setting. The main research question targeted the potential link between parent and child emotion regulation skills. The present study improves upon the literature of emotion regulation studies by (a) selecting families based on key demographic variables, (b) incorporating a multimodal method of emotion regulation measurement, and (c) analyzing parent and child emotion regulation components.

\section{Method}

\section{Participants}

Two samples of parent and child dyads were recruited for this study through clinical referrals and community service providers. All family dyads included a legal guardian and a child between the ages 2 and 8 years. Families were collected from two rural populations in the United States (Table 1).

The group of families with children with disruptive behaviors $(n=34)$ was referred to the study by clinicians in university-based and community mental health clinics. These clinical families were referred for parent training services and had received 3 or fewer treatment sessions. The identified caregiver completed a battery of self-report measures followed by a structured behavioral observation of the parent-child dyad.

Another group of families $(n=26)$ with children displaying typical behavior was recruited through daycares, clubs, flyers, and Head-Start programs in the same communities as the clinical families. Families could not to be currently seeking parent training services. Children in these families were screened-out if parents reported high levels of behavior problems. Table 2 reports descriptive statistics by group. Children diagnosed with autism spectrum disorder were excluded from both groups given inherent emotion regulation difficulties.

Families in the sample $(N=71)$ were collected and compared between groups in a blocking method. Clinical data collection began prior to the nonclinical comparison group with groups blocked based on demographic measures (Table $1 \& 2$ ). Blocking for demographic 
characteristics was performed at approximately each third of data collection. This method worked to eliminate alternative hypotheses and potentially confounding variables that could decrease threats to internal validity (Kazdin, 1998). Families were screened prior to data collection for child behavior problems. Data for a number of families not meeting inclusion criteria were eliminated $(n=4)$. Families collected during blocking periods that did not correspond to the clinical group were also excluded (low-income, minority families; $n=7$ ) to allow for similar groups and a final comparable sample $(N=60$, see Table 1$)$.

Researchers obtained permission to contact forms from interested participants prior to phone screenings. Families were informed of their rights and details of the study during the consent process. Parents completed consent paperwork and age-appropriate children (7 and older) completed the assent process according to the university's institutional review board standards. All participating caregivers were compensated for their time and children received a small toy. All measures and behavioral observations were completed in one session.

\section{Measures}

Family characteristics. Family characteristics were assessed with the following two measures to determine if any differences existed between groups (Eyberg \& Pincus, 1999). Information on family characteristics was obtained via a questionnaire completed by the caregiver. The questionnaire covered details about the caregiver's sex, age, ethnicity, level of education, household yearly income, relationship to the child, and marital status. The questionnaire also assessed for child sex, age, and ethnicity.

Differences in child behavior problems were obtained using the Eyberg Child Behavior Inventory (ECBI; Eyberg \& Pincus, 1999), a 36-item parent-report measure. Caregivers rated the frequency of child behaviors using a seven-point Likert scale from 1 (never) to 7 (always) which forms an Intensity Scale. Each item also required caregivers to report if they considered a 
presenting behavior as a problem (yes/no) to create a Problem Scale. Ages for the measure range from 2 to 16 years of age (Eyberg \& Pincus, 1999).

The ECBI has been shown to have robust measures of reliability and validity across numerous studies. Reports for test-retest reliability over 10 months for the intensity scale are strong (.75; Eyberg \& Pincus, 1999). Intensity Scale and Problem Scale inter-rater reliability have also shown positive correlations, .86 and .79, respectively (Eyberg \& Pincus, 1999) and for measures of internal consistency, .95 and .93, respectively (Colvin, Eyberg, \& Adams, 1999). The ECBI was found to have positive predictive power for its components of inattention (.85), opposition (.80), and conduct problems (.63; Weis, Lovejoy, \& Lundahl, 2005). The ECBI demonstrated concurrent validity with the CBCL's internalizing and externalizing subscales across preschool, elementary, and adolescent-aged children (.75 and .67, respectively; Boggs, Eyberg, \& Reyonlds, 1990).

Child Behavior Checklist (CBCL). The Child Behavior Checklist (CBCL; Achenbach \& Rescorla, 2000; 2001) was used to assess behaviors, emotions, and competencies exhibited in a child via parent-report. The CBCL has shown strong criterion validity even when parents present with problems themselves (Friedlander, Weiss, \& Traylor, 1986). The CBCL had strong test-retest reliability ratings ranging from .95 to 1.0 (Achenbach \& Rescorla, 2001). Parents in this study rated their children's activities, school performance, and social relationships on a three-point Likert scale ranging from 0 , the listed trait or activity is not an accurate representation of the child to 2, "very true or often true." The CBCL's Internalizing subscale (e.g., anxiety, depression, bodily pains, emotional responses, sensitivity), Externalizing subscale (e.g., aggression problems, attention deficits), and an overall score (general problematic symptoms) were used. The Internalizing and Externalizing behavior subscales have strong internal consistency with scores of .90 and .94, respectively (Achenbach \& Rescorla, 2001). 
The present study utilized both the CBCL for ages 1.5-5 and for ages 6-18. The version for children ranging from 1.5 through 5 years was a 99 question design completed by caregivers to measure behaviors of these children. The version designed for children aged 6 through 18 was a 112 question design assessing child behaviors relevant for this population of children.

Parenting Stress Index- Short Form (PSI). The Parenting Stress Index- Short Form (PSI; Abidin, 1990), a 36 item self-report measure, was used to assess stress levels from responsibilities related raising a child. The PSI was validated for children ranging from 3 months to 12 years of age (Abidin, 1990). The PSI has been shown to be highly correlated with the 120item Parenting Stress Index full form, $r=.94$ (Abidin, 1990). The PSI short form contains four subscales to measure Parental Distress, Parent-Child Dysfunction (Dysfunction), Difficult Child, and Total Stress levels. Internal consistency estimates for the PSI short form have shown reliability of the scales, $\alpha>.60$ (Whiteside-Mansell et al., 2007). Validity coefficients of the PSI scales were assessed at child ages of 15, 25, and 37 months and showed strong relationships of family, parenting, maternal, and child characteristics and general distress (Whiteside-Mansell et al., 2007). Studies using the PSI have shown good levels of test-retest reliability over a one year period (.55 child, .70 parent; Loyd \& Abidin, 1985). Other reliability measures have found the PSI to have high levels of reliability for both the parent category (.55-.80) and the child category (.62-.70; Loyd \& Abidin, 1985).

Difficulties in Emotion Regulation Scale (DERS). The Difficulties in Emotion Regulation Scale (DERS; Gratz \& Roemer, 2004) was used by caregivers as a self-report to assess emotion regulation capabilities. The DERS has been shown to yield high alpha scores for test-retest reliability (.88) and overall internal consistency (.93; Achenbach \& Rescorla, 2000). Numerous studies have used this 36-item questionnaire to evaluate emotion regulation capabilities in different populations including maltreating parents (Robinson et al., 2009), teachers (Casler, 2006), individuals with social anxiety (Rusch, Westermann, \& Lincoln, 2012) 
and posttraumatic stress (Bonn-Miller, Vujanovic, Boden, \& Gross, 2011). The six DERS subscales have demonstrated high levels of internal consistency (Cronbach's $\alpha=.80-.89$ ). Five of these six subscales have also demonstrated moderate to strong levels of intercorrelation, $r=$ .32 to $r=.63$ (Gratz \& Roemer, 2004). Additionally, the DERS subscales have significantly correlated with other emotion regulation measures of negative mood regulation, from $r=.34$ to $r$ $=.69$ (Gratz \& Roemer, 2004). The DERS was designed to indicate emotion dysregulation for six separate domains using a five point Likert scale model. Respondents read general statements related to emotion and scored the items from 1 where the individual had the experience "Almost never (10-15\%)" to 5 where the individual had the experience "Almost always (91-100\%)" (Gratz \& Roemer, 2004). Higher scores on the DERS indicated higher problems related to emotion regulation. Scores ranged from 36, for most successful emotion regulation capabilities, to 180 , for highly emotionally dysregulated individuals. Caregivers are scored on six domains: (a) lack acceptance of emotional responses (Nonaccept), (b) use goal-directed behaviors (Goals), (c) have difficulties controlling one's impulses (Impulse), (d) lack awareness of emotional responses (Aware), (e) have limited accessibility to effective emotion regulation strategies (Strategies), and (f) lack clarity for emotional responses (Clarity). The present study examined overall scores as well as scores for each of the six domains.

Emotion Regulation Checklist (ERC). The Emotion Regulation Checklist (ERC; Shields \& Cicchetti, 1997), a 24-item parent-report questionnaire, was used by caregivers to assess their child's ability to manage emotional experiences. It has been used repeatedly in studies of childhood emotion regulation since its establishment in different populations (Adrian, Zeman, \& Veits, 2011). Parents reported on each item based on a scale ranging from 1 (never) to 4 (always). Within the ERC, two subscales were used in addition to an overall rating. The Lability/Negativity subscale measured a child's inflexibility, frequent mood shifts, and inappropriate negative expressions. The Emotion Regulation subscale measured empathy, 
emotional self-awareness, and appropriate emotional expression. The ERC has been shown to accurately distinguish between regulated and dysregulated subjects, and maltreated and nonmaltreated children (Shields \& Cicchetti, 1997). Additionally, the measure has been used to assess children's poorer emotion regulation with depressed mothers (Blandon, Calkins, Keane, \& O’Brien, 2008), children with anxiety disorders (Suveg \& Zeman, 2004), and has also been used to correlate emotion regulation and displays of appropriate behavior (Onchwari \& Keengwe, 2011).

The overall ERC has strong reliability (.89) as does the Lability/Negativity subscale (.96) and the Emotion Regulation subscale (.83;). In addition to convergent validity being established for the ERC through observation ratings of children's emotion regulation skills, the ERC also has been shown to have discriminant validity from other related emotional constructs (e.g., autonomy; Shields \& Cicchetti, 1997).

Dyadic Parent-Child Interaction Coding System (DPICS). The Dyadic Parent-Child Interaction Coding System, Fourth Edition (DPICS-IV; Eyberg, Nelson, Ginn, Bhuiyan, \& Boggs, 2013) was used as an observational measure specifically targeting parent-child exchanges and responses during three separate five-minute one-on-one interactions. During the first of the three situations, the child initiated and led a play interaction with the parent (Child Led PlayCLP). In the second five-minute interaction, the parent was instructed to take control away from the child and lead the play interaction by encouraging the child to play according to the parent's rules (Parent Led Play_-PLP). The third interaction consisted of the parent instructing the child to clean up the toys without the parent's assistance (Clean-Up). Undergraduates trained in the DPICS transcribed the interactions and coded behavioral categories. The DPICS was used to measure three components of parent and child behavior. First, researchers measured parent's use of negative talk (composite of statements expressing negativity toward the child and the child's actions) and commands (the total number of directing statements to control the physical or verbal 
behaviors of the child) across all three situations (CLP, PLP, Clean-Up) as measures of negative parenting behaviors. Second, researchers recorded a child compliance percentage across all three situations by dividing the total times the child complied with a command by the total number of commands given by the parent. Third, the DPICS measured child disruptive behaviors (e.g., yelling, whining) during the situations in the session.

The DPICS categories have each been shown to be reliable and valid in live settings and video recorded observations (Eyberg, Nelson, Duke, \& Boggs, 2005). The measure has been shown to accurately discriminate between clinically referred and nonclinical children (Eyberg et al., 2005) as well as clinically referred and nonclinical mother-child pairs (Robinson \& Eyberg, 1981). Robinson and Eyberg (1981) also found high levels of inter-rater reliability for both child (.92) and parent behaviors (.91). Codes during the PLP and Clean-Up tasks for negative talk and parent praise had high test-retest reliability over the course of one week (Eyberg et al., 2005).

\section{Procedure}

The study was approved by a university's Institutional Review Board. In both groups, families completed the demographics form and ECBI. These measures were used to block the groups on key demographics. The measures, including the CBCL and PSI also were incorporated as preliminary markers of group features. All caregivers then completed measures related to emotion regulation including the DERS and ERC. Next, families participated in a structured behavioral observation for coding of dyadic interactions. Two graduate student coders and a team of highly trained undergraduate coders completed all DPICS coding. All coders were trained using The Abridged Workbook: Coder Training Manual for the Dyadic Parent-Child

Interaction Coding System ( $3^{\text {rd }}$ ed., Fernandez, Chase, Ingalls, \& Eyberg, 2006). Kappa was .94 between coders for behavioral observations. If multiple children in a home met the criteria to participate in the study, one child was chosen at random to participate. Participants in the two groups underwent the same procedures for pretreatment assessment and observation measures. 


\section{Results}

\section{Preliminary Analyses}

The demographic questionnaire provided descriptive data for preliminary analyses for overall characteristics of the sample (see Table 1) and between group differences (Table 2). Demographic variables examined for caregivers included sex, ethnicity, marital status, household income, education, and Child Protective Services (CPS) involvement. Assessed child demographics included sex, ethnicity, and age (see Table 1). No differences were found for any of the measured variables aside from CPS involvement (Table 2), indicating clinical families were more likely to be involved in CYS than nonclinical comparisons. Both groups were also compared on child behavior problems to confirm the groups were truly distinct on children's externalizing behavior problems. As expected, children in the clinical group presented with higher intensity behavior problems $(T=70-71)$ than their comparison group $(T=46)$ as determined by the ECBI. Caregivers of children in the clinically referred sample also saw the behaviors as more problematic $(T=69)$ on the ECBI than the comparison caregivers $(T=45$; see Table 2).

Analyses were run to confirm that groups differed on core characteristics frequently cooccurring for families of children with externalizing behavior disorders. Both child problem behaviors (externalizing, internalizing) and parental stress levels were measured. Scores on the CBCL indicated more problematic externalizing behaviors for the clinical group than the comparison group as well as internalizing behaviors (Table 3). Parenting stress levels were significant on a number of factors with parents referred for parent-training having significantly more problems with Parental Distress, parent-child dysfunctional interaction, and difficult children. In addition, clinical parents had higher Total Stress levels compared to nonclinical families $\left(90-95^{\text {th }}\right.$ percentile vs. $50^{\text {th }}$ percentile, respectively; Table 3$)$.

\section{Parental Emotion Dysregulation}


As hypothesized, parents of children with behavior problems had increased rates of dysregulated emotion as measured by higher total scores on the DERS (Gratz \& Roemer, 2004) compared to nonclinical comparisons (see Table 3). Measures of dysregulated emotion were higher for parents referred for parent training including Difficulties Engaging in Goal-Directed Behaviors, Impulse Control Difficulties, and Limited Access to Emotion Regulation Strategies; however, three subscales did not meet our initial hypothesis including Nonacceptance of Emotional Responses, Lack of Emotional Awareness, and Lack of Emotional Clarity. Overall, the findings indicated that parents of children with behavior disorders had more emotional regulation problems than parents of children without behavior problems.

\section{Child Emotion Regulation}

As hypothesized, clinically-referred children had lower emotion regulation capabilities than the nonclinical comparison children indicated by lower scores on the ERC (Shields \& Cicchetti, 1997). Parents in the clinically referred group rated their children as having greater problems with negativity, and reported significantly less regulatory abilities for emotional regulation (Table 3).

\section{Relationship of Parental and Child Emotion Regulation}

Correlations were conducted to determine which factors were significantly related to variance for both child emotion regulation (as measured with the ERC) and parental emotion regulation (as measured with the DERS). It was also hypothesized that similar factors would be associated with both the outcomes for the DERS and the ERC. As hypothesized, a significant correlation was found between parental and child emotion regulation abilities. Using the total score subscales for the DERS and ERC, findings indicated a negative correlation between parental emotion dysregulation and child emotion regulation suggesting that greater dysregulation in the parents was related to lower emotion regulation in the child. Both the DERS and ERC were correlated with the CBCL Internalizing and Externalizing subscales, and PSI 
Total Stress subscale. The DERS was positively correlated with child internalizing behavior problems (CBCL Internalizing) indicating that higher levels of parental emotion dysregulation were correlated with higher rates of children's problem internalizing behaviors. The ERC was negatively correlated with CBCL Internalizing indicating that higher levels of child emotion regulation were associated with lower levels of internalizing problem behaviors in children. The observational measure of Negative Talk for the DPICS was also correlated with both the DERS and ERC. These results suggest that parents with greater levels of emotion dysregulation (DERS) used more negative verbalizations and children with greater levels of emotional dysregulation (ERC) had parents who used more negative verbalizations during their structured play interactions. The ERC was also found to negatively correlate with the DPICS Child Disruptive Behavior (Table 4). Children who had more emotion dysregulation displayed more disruptive behaviors. Selected demographic factors (i.e., parent emotion regulation, child internalizing and externalizing behaviors, parenting stress, parental negative verbalizations and commands, child disruptive behaviors and compliance) were examined to determine if they were associated with the main outcome variables (Table 5).

Using variables that correlated significantly with the DERS and ERC, two multiple regressions were conducted to determine the strongest predictors of both parental emotion regulation and child emotion regulation. Analyses were run using the entire sample (i.e., both groups combined). Variables entered into the DERS model included the ERC, CBCL Internalizing and Externalizing subscales, PSI, and DPICS Negative Talk. For parental emotional dysregulation (DERS), the highest variance was accounted for with the PSI Total Stress measurement (Table 6). Parental stress was the greatest predictor of parental emotion regulation capabilities. Variables entered into the ERC regression model included the DERS, CBCL Internalizing and Externalizing subscales, PSI Total Stress, DPICS Negative Talk, DPICS child disruptive behavior, and education. Because education was found to be significantly 
associated with the ERC, education was included in the final regression analyses. The highest variance for child emotion regulation (ERC) was accounted for with the measure of CBCL Externalizing (Table 7). Child externalizing behaviors were found to be the greatest predictor of children's emotion regulation abilities.

Another correlation matrix was created to find variables correlated with the DERS and ERC between the different groups (Table 8). Fisher $r$ to $z$ transformations were conducted to compare correlation coefficients on similar variables between the two groups (e.g, clinical group's ERC and DERS correlation coefficient versus the comparison group's). No variable correlations were significantly different between groups suggesting that all variables correlated similarly between the two groups. Significant correlations for the clinical group's parental emotion dysregulation (DERS) included PSI Total Stress and DPICS Negative Talk (Table 6). Findings indicated clinical parents had higher levels of stress and used more negative verbalizations with their child if they had higher rates of emotion dysregulation. DERS results for the comparison sample had significant correlations with the ERC, CBCL Internalizing scale, and PSI Total Stress (Table 6). Therefore, increased rates of emotion dysregulation in comparison samples were related to more emotion dysregulation and internalizing problems in their children as well as increased levels of parental stress. Significant correlations for child emotion regulation (ERC) of the clinical group included the CBCL Internalizing, CBCL Externalizing, PSI Total Stress, and DPICS Command. Clinical children's higher rates of emotion dysregulation were related to higher rates of internalizing and externalizing behavior problems. These children had parents with higher parenting stress levels and who used more commands with their children. ERC results for the comparison sample had significant correlations with CBCL Internalizing, CBCL Externalizing, and PSI Total Stress. These results indicate that comparison sample children with higher rates of emotion regulation had less internalizing and externalizing behavior problems, and had parents with less parenting stress. 
Another set of multiple regressions was run using the original variables defined by the combined-group sample correlation matrix to explore the measures of parental and child emotion regulation (Table $9 \& 10$ ). Analyses yielded outcomes for both the clinical and comparison groups. For parental emotion regulation, both the clinical and comparison group had the most variance accounted for by parental stress (PSI), and, respectively (Table 9). For child emotion regulation, the measure of child externalizing problem behaviors (CBCL Externalizing) was a significant predictor, but only for the clinical group (Table 10). Findings indicate important similarities and differences between the two samples.

A correlation matrix was run to further explore the relationship between parental emotion dysregulation and other significant factors. The six DERS subscales were used (see Table 11). The DERS subscales of Goals, Impulse, and Strategies were all significantly negatively correlated with child emotion regulation (ERC Total). These correlations indicate poorer parental skills in goal-directed behavior, impulse control, and limited emotion regulation strategies were associated with greater child emotion regulation difficulties. These same subscales were also significantly positively correlated with the CBCL internalizing and externalizing problem child behaviors. All DERS subscales were significantly correlated with parenting stress except for the Aware subscale. Correlations with DPICS Negative Talk yielded significant outcomes for Nonaccept, Impulse, Strategies, and Clarity subscales.

\section{Child Abuse Sample}

Exploratory analyses were run to determine differences in clinically referred families who were involved with CPS $(n=10)$ compared to clinical families never involved in CPS $(n=$ 24). Means for the DERS and the ERC were compared between the two groups (Table 12). Groups were not statistically significantly different on either parent or child emotion regulation. However, findings indicated a trend with CPS children having lower emotion regulation capabilities $(M=2.38)$ than non-CPS referred children $(M=2.62)$. Cohen's effect size value $(d=$ 
.66) suggests a moderate to high practical significance. Groups also did not differ significantly for parent emotion dysregulation.

\section{Discussion}

The current study sought to determine the relationship of emotion regulation between parents and their children with and without externalizing behavior disorders. The study explored the factors correlated to child and parent emotion regulation abilities and determined the greatest predictors for both parental and child emotion regulation. Furthermore, a link possible link was found between both parents' and children's emotion regulation capabilities.

The current study found a link between the DERS and the ERC, indicating higher rates of parental dysregulation has a patterned lower rate of child emotional regulation abilities. This finding, along with the large number of factors found to correlate with both measures of emotion regulation, helps explain the link between emotion regulation abilities of parents and their children. In further analyses, child emotion regulation was found to be correlated with specific components of parental emotion dysregulation including parental difficulty in engaging in goaldirected behavior, impulse control difficulties, and lack of emotion regulation strategies. It is possible that certain components of parental abilities play a greater role in influencing child emotion regulation skills. One explanation for the present correlation of emotion regulation similarities cited in the literature is the process of parental modeling. Parents provide specific attention and model behaviors for their children thus allowing their children to develop an appropriate understanding of emotion and socialization. Ideally, positive parenting practices which foster appropriate emotion socialization and involve treating a child's emotions with acceptance, warmth, and guidance to help the child handle emotions appropriately (Cole et al., 2008). Individual differences in emotion regulation emerge from the socialization of appropriate emotion-related behaviors by parents through modeling, reinforcement, and discipline (Calkins, 
1994). Parents then provide the model for children to base all of their emotion regulatory behaviors as they explore their environment.

While parents can provide positive modeling behavior, additional findings have indicated similarities in emotion control between parents and children when both the parent and the child experience difficulty controlling their emotions (Cole, Michel, \& Teti, 1994).Another explanation for the link between parental and child emotion regulation capabilities stems from the potential bidirectionality of the coercive parenting style (Patterson \& Capaldi, 1991). Calkins (1994) found differences in internal and external displays of emotion regulation and that these differences were directly connected to the interplay between children and their parents. Cole, Teti, and Zahn-Waxler (2003) also documented the occurrence of mutual emotion regulation where children responded to the emotional cues of their parents. Mothers' positive responses were often found to be reciprocated by their preschoolers. Similarly, maternal negative emotions (e.g., anger) were also reciprocated by children. This parallel negative behavior significantly predicted the outcomes of children's conduct problems (Cole, Teti, \& Zahn-Waxler, 2003). Gaensbauer and Mrazek (1981) determined that positive sharing, which they found occurred often between parents and children, was a primary mechanism for helping the child to develop adaptive emotion regulation skills. In a similar study, mothers who more frequently exhibited positive emotions had children who exhibited more effective emotion regulation (Garner, 1995).

As the coercive cycle theory describes, parents and children can become entangled in an increasingly problematic interchange of verbal and behavioral strategies to control a situation (Patterson \& Capaldi, 1991), which can ultimately result in physical abuse (Urquiza \& McNeil, 1996). Interestingly, the two groups in the current study varied significantly in their involvement with Child Protective Services, with clinically referred families having more referrals prior to and during the data collection; these findings potentially reflected more dysregulated and abusive environments. In addition, further analyses indicated a potential trend toward lower child 
emotion regulation capacities for those clinical families involved with Child Protective Services. Maltreated children have shown significantly higher levels of internalizing symptomology, higher levels of emotion lability/negativity, and lower levels of emotion regulation as compared to their nonmaltreated counterparts (Kim-Spoon, Cicchetti, \& Rogosch, 2013). Emotionality plays a significant role in family interactions and highly dysregulated families may place children at an increased risk of maltreatment.

Abusive parenting can lead to additional problematic outcomes for a child. Characteristic behaviors of maltreating parents include criticism, punishment, or minimization of a child's emotional expression (Berlin \& Cassidy, 2003). These negative parenting styles are associated with child emotional suppression, avoidant coping, and a disinterest to seek support, all of which have been conceptualized as poor emotion regulation strategies (Shipman et al., 2007). Children from abusive households may struggle with emotion regulation and be at increased risk for negative future outcomes.

The results of the study indicated higher rates of emotion dysregulation for children with externalizing behavior disorders. While some areas of the parenting emotion dysregulation measure (DERS) were shown to be statistically significantly different between groups, other areas did not show the expected differences. The failure to find significant differences between groups in relation to nonacceptance of emotional responses as well as lack of emotional awareness and clarity may point to a unique characteristic in the present study's clinical sample. It is possible that targeting families of children with and without externalizing behavior problems may have ignored a portion of emotional dysregulators who over-control emotional responses. Some research has indicated that subscales of the emotion regulation measure have been related to differences between internalizing and externalizing behavior problems (Neumann, van Lier, Gratz, \& Koot, 2010). No previous literature exists addressing emotion regulation with the 
DERS and a sample of parents with potential emotion regulation problems. This may also limit the understanding of this finding.

Notably, it should be recognized that differences may arise from the sample selected for this study. Significant differences in the expression of emotion dysregulation exist between children with externalizing behavior problems and those with internalizing behavior problems (Macklem, 2008). While neither external nor internal problems may be mutually exclusive, distinct characteristics may exist. These distinctions may be especially prevalent in a sample selected for the presence of externalizing behavior problems. Macklem (2008) highlighted differences in children experiencing the two categories. For example, externalizing and internalizing children may both respond to negative emotions with aggressive strategies, but only internalizing children typically utilize avoidant strategies as well (Macklem, 2008). The present sample characteristics should be considered when interpreting the findings. An important finding from this study indicated that both parents' and children's emotion dysregulation was associated with DPICS coded Negative Talk. Only one other preliminary study found a similar correlation between the use of negative talk and child outcomes. Richerson (2008) found that when children and parents participated in the DPCIS Clean-Up task, the mothers' use of negative talk was the most significant predictor of the child's refusal to comply with parental commands. Mothers who used harsh discipline and experienced high stress levels were unable to teach their children more productive strategies to manage problem behaviors (Richerson, 2008). It is possible that one way parental dysregulation is manifested is through negative verbalizations. This parental dysregulation, in turn, could play a role in the development and maintenance of child externalizing problem behaviors. Behavioral observations such as negative talk may be crucial in the future to identify parental dysregulation during parent interactions with a child.

Interestingly, the presence of problematic externalizing behaviors explained the greatest proportion of variance of children's emotional dysregulation according to a regression analyses. 
This relationship was strongest in the clinical, externalizing behavior problem group. This finding supports previous research showing emotionally dysregulated children have difficulties behaviorally and physiologically self-soothing under emotionally stressful situations (Eisenberg, Cumberland, \& Spinrad, 1998). Moreover, emotional dysregulation can lead to and worsen social, behavioral, and emotional problems (Cummings, Keller, \& Davies, 2005). Similarly, conduct problems in children have been shown to negatively correlate with adaptive child emotion regulation strategies (Walton \& Flouri, 2010). A study by Volk-Stowell (2006) looked into the interaction of conduct problems and emotion regulation through scores on the ERC. Participants with conduct problems had higher levels of dysregulation and were less successful in using their emotions adaptively. It is possible that emotion regulation may be represented by externalizing behaviors for young children not yet at the developmental stage to self-reflect on emotionality.

This study found that parental emotion dysregulation was highly predicted by total measures of parental stress. The results of this investigation showed that parental stress was a significant predictor of parental emotion regulation abilities for both clinical and comparison samples. Some research has indicated that parents who have difficulty coping with stress may have more issues with emotion regulation (Deater-Deckard, 2004) and that emotion regulation may be one's ability to react to these stressful events in an adaptive, or resilient manner (Troy \& Mauss, 2011). However, few research studies exist that indicate a direct relationship between parental stress and emotion regulation. More research studies have instead shown a strong correlation with parental stress and child behavior problems (Anastopoulos, Guevremont, Shelton, \& DuPaul, 1992; Buodo, Moscardino, Scrimin, Altoé, \& Palomba, 2013; WebsterStratton, 1990) as well as parental abilities (DeGarmo, Patterson, \& Forgatch, 2004). Stressed parents can utilize parenting strategies such as inconsistent and harsh discipline which have negative future outcomes for the children exposed to such practices (Patterson, Reid, \& Dishion, 
1992). The expression of stress is highly linked to parents' emotion regulation capabilities which can significantly affect how parents interact and model emotional behavior with their children. Notably, the current study examined the relationship between the DERS and ERC. The correlation between the two measures has seldom been explored. The current authors found only one other study that examined the DERS and ERC (Seymour et al., 2011). Seymour and colleagues correlated child (ages 10-14) self-reports on the DERS with parent-reports of the child on the ERC. Seymour found the DERS total score and ERC Lability/Negativity score were positively correlated, $r=0.41$, indicating that a child and parent had a mutual understanding of a child's emotion dysregulation (2011). Like the current study, Seymour and colleagues had parents complete the Emotion Regulation Checklist to describe emotion regulation characteristics of their children, however, children completed the DERS for their own emotion regulation issues (rather than a parental self-report). The present study explored the relationship between both child and parental emotion regulation using these key measures.

\section{Limitations}

Several limitations were present in this study. The blocking method utilized for collecting participants was complicated as data collection for the clinical group began before nonclinical comparisons were initiated. Characteristics became harder to control for and a number of families had to be eliminated from interpretation to prevent mismatched grouping. The study participants were drawn from a rural population across two states. Families had children from 2- to 8-years-old, with some underrepresentation of ethnic minorities. While $80 \%$ of the families utilized in this study were Caucasian, the concern is tempered somewhat as the sample controlled for other important factors such as socioeconomics. While previous literature has looked at a number of different links between parent and youth emotions, the field lacks the proper between-group study matching socio-economic status for clinically referred and nonclinical families. This linkage is critical as it is often intertwined with emotion regulation 
variance (Koblinsky, Kuvalanka, \& Randolph, 2006). Additionally, existing studies exploring the relationship between emotion regulation in parents and children are in either typically developing families or in clinically referred families, but few studies explore differences between the two groups to see if parent to child transference of emotion regulation occurs in each environment. This article collected and compared between group differences in relation to emotion regulation.

The present sample included children younger than those typically seen in emotion regulation studies (Bariola, Hughes, \& Gullone, 2012; Hourigan, Goodman, \& Southam-Gerow, 2011). Given that child externalizing behavior disorders were found to strongly predict emotion dysregulation, our sample adds to the current literature of how younger children express emotion regulation. It is important to note that this study also focused on one type of emotion regulation (i.e., lack of control with externalizing behavior problems). The study did not target families of children that had over-controlled regulation (i.e., internalizing problems). Therefore, generalization to other forms of emotion dysregulation may not be applicable from this study.

The frustration-inducing task utilized in this study was the DPICS. While Clean-Up procedures yielded some frustration for a number of children, other behavioral observations of frustration have been validated and used with success (Calkins, Dedmon, Gill, Lomax, \& Johnson, 2002; Cole et al., 1994; Silk, Steinberg, \& Morris, 2003; Stifter \& Braungart, 1995). Although other methods have more research support, this study utilized an important multimethod approach. Throughout the literature, researchers commonly utilize other-reports (e.g., parent, teacher) or observations to measure child emotion regulation. Researchers have suggested that when determining familial interactions, clinicians should use multimethod evaluations because the comprehensive approach provides better overall data than self-report or observational measures alone (Henggeler, Borduin, \& Mann, 1987). When evaluating a multifaceted construct like emotion regulation, the inclusion of both behavioral observations and 
self-reports should enhance validity and reliability of the measurement, while also providing the opportunity to directly compare child and parent emotion regulation.

\section{Future Directions/ Concluding Remarks}

The present findings suggest that emotion regulation is an important factor when working with children with externalizing behavior problems and their parents. Because emotion regulation can play such a critical role within the family dynamic, parent training treatment should potentially attend to emotion regulation problems. At the very least, it is suggested that more research should be done to measure emotion regulation outcomes to determine if parent training programs (with the purpose of reducing child externalizing behaviors) help in the reduction of emotion regulation problems for both parents and their children. Timeout procedures could already help children gain the self-control they did not have prior to treatment initiation. Parent training may also help parents learn to speak calmly, thus reducing negative parenting practices often associated with stress and emotion dysregulation (Deater-Deckard, 2004; Patterson, Reid, \& Dishion, 1992). Although these methods may already help reduce emotion dysregulation, more studies need to focus on outcome measures to indicate success or gaps in current treatments.

Future directions should also focus on emotion regulation similarities and differences related to children with internalizing behavior problems. Important differences have been previously found in the literature (Macklem, 2008), however more research in this area would create a wider depth in understanding the dynamics of emotion regulation in these families.

Parental stress may also be a significant factor in the treatment of individuals with emotion regulation problems for parents of children with or without externalizing behavior problems. Including a parental stress component of treatment to those parents involved in individual treatments such as cognitive behavioral therapy for emotion dysregulation may help increase benefits of mental health therapy. Moreover, prevention strategies targeted at parents-to- 
be may help increase the likelihood parents will appropriately regulate their emotions for their children.

Finally, future research studies should explore and refine observational measures of child emotion regulation to allow for easier measurement in both research and clinical settings. It is also suggested that future research continues to explore the potential link between abusive family populations (Kennedy, Kim, Tripodi, Brown, \& Gowdy, 2014). Emotion regulation has a critical role in the relationship between parental and child interactions and future outcomes. More research is needed to continue to map out the direct role emotion regulation plays in the powerful relationship of a parent and a child. 


\section{References}

Abidin, R. R. (1990). Parenting Stress Index / Short Form. Lutz, FL: Psychological Assessment Resources, Inc.

Achenbach, T. M., \& Rescorla, L. A. (2000). Manual for ASEBA preschool forms \& profiles. Burlington, VT: University of Vermont, Research Center for Children, Youth, \& Families.

Achenbach, T. M., \& Rescorla, L. A. (2001). Manual for ASEBA school-aged forms \& profiles. Burlington, VA: University of Vermont, Research Center for Children, Youth, \& Families.

Adrian, M., Zeman, J., \& Veits, G. (2011). Methodological implications of the affect revolution: A 35-year review of emotion regulation assessment in children. Journal of Experimental Child Psychology, 110(2), 171-197.

American Psychiatric Association. (1994). Diagnostic and statistical manual of mental disorders (4th ed.). Washington, DC.

Anastopoulos, A. D., Guevremont. D.C., Shelton, T. L., \& DuPaul, G. J. (1992). Parenting stress among families of children with attention deficit hyperactivity disorder. Journal of Abnormal Child Psychology, 20, 503-510.

Bariola, E., Hughes. E. K., \& Gullone, E. (2012). Relationships between parent and child emotion regulation strategy use: A brief report. Journal of Child and Family Studies, $21(3), 443-448$.

Berlin, L. J. \& Cassidy, J. (2003). Mothers' self-reported control of their preschool children's emotional expressiveness: A longitudinal study of associations with infant-mother attachment and children's emotion regulation. Social Development, 12(4), 477-495.

Blair, C., \& Diamond, A. (2008). Biological processes in prevention and intervention: The 
promotion of self-regulation as a means of preventing school failure. Development and Psychopathology, 20(3), 899-911.

Blandon, A. Y., Calkins, S. D., Keane, S. P., \& O’Brien, M. (2008). Individual differences in trajectories of emotion regulation processes: The effects of maternal depressive symptomatology and children's physiological regulation. Developmental Psychology, 44(4), 1110-1123.

Boggs, S. R., Eyberg, S., \& Reynolds, L. A. (1990). Concurrent validity of the Eyberg Child Behavior Inventory. Journal of Clinical Child Psychology, 19(1), 75-78.

Bonn-Miller, M. O., Vujanovic, A. A., Boden, M. J., \& Gross, J. J. (2011). Posttraumatic stress, difficulties in emotion regulation, and coping-oriented marijuana use. Cognitive Behaviour Therapy, 40, 34-44.

Buodo, G., Moscardino, U., Scrimin, S., Altoé, G., \& Palomba, D. (2013). Parenting stress and externalizing behavior symptoms in children: The impact of emotional reactivity. Child Psychiatric Human Development, 44, 786-797.

Burns, E. E., Fischer, S., Jackson, J. L., \& Harding, H. G. (2012). Deficits in emotion regulation mediate the relationship between childhood abuse and later eating disorder symtoms. Child Abuse \& Neglect, 36(1), 32-39.

Calkins, S. D. (1994). Origins and outcomes of individual differences in emotion regulation. Monographs of the Society for Research in Child Development, 59, 53-72.

Calkins, S. D., Dedmon, S. E., Gill, K. L., Lomax, L. E., \& Johnson, L. M. (2002). Frustration in infancy: Implications for emotion regulation, physiological processes, and temperament. Infancy, 3(2), 175-197.

Calkins, S. D., Smith, C. L., Gill, K. L., \& Johnson, M. C. (1998). Maternal interactive style across contexts: Relations to emotional, behavioral, and physiological regulation during toddlerhood. Social Development, 7(3), 350-369. 
Cao, H., Guan, M., \& Zhang, J. (2007). Emotion regulation style of juvenile delinquents. Chinese Journal of Clinical Psychology, 15(5), 539-542.

Casler, E. N. (2006). A comparison of classroom teachers' self-regulation behaviors in relation to effective teacher practices used during instruction. Dissertation Abstracts International Section A: Humanities and Social Sciences, 67(2-A), pp. 457.

Cole, P.M., Dennis, T.A., \& Smith-Simon, K.E., \& Cohen, L.H. (2008). Preschoolers' emotion regulation strategy understanding: Relations with emotion socialization and child selfregulation. Social Development, 18, 324-352.

Cole, P. M., Michel, M. K., \& Teti, L. O. (1994). The development of emotion regulation and dysregulation: A clinical perspective. Monographs of the Society for Research in Child Development, 59(2), 73-100.

Cole, P. M., Teti, L. O., \& Zahn-Waxler, C. (2003). Mutual emotion regulation and the stability of conduct problems between preschool and early school age. Development and Psychopathology, 15(1), 1-18.

Colvin, A., Eyberg, S.M., \& Adams, C. (1999). Restandardization of the Eyberg Child Behavior Inventory. Gainesville: University of Florida, Child Study Laboratory. Retrieved from http://pcit.phhp.ufl.edu/Measures.htm

Cummings, E. M., Keller, P. S., \& Davies, P. T. (2005). Towards a family process model of maternal and paternal depressive symptoms: Exploring multiple relations with child and family functioning. Journal of Child Psychology and Psychiatry, 46, 479-489.

Dean, A. C., \& London, E. D. Cerebral deficits associated with impaired cognition and regulation of emotion in methamphetamine abuse. In J. D. Kassel (Ed.), Substance abuse and emotion (pp. 237-257). Washington, DC US: American Psychological Association.

Deater-Deckard, K. (2004). Parenting stress. New Haven, CT: Yale University Press.

DeGarmo, D. S., Patterson, G. R., \& Forgatch, M. S. (2004). How do outcomes in a specified 
parent training intervention maintain or wane over time? Prevention Science, 5, 73-89.

Eisenberg, N., Cumberland, A., \& Spinrad, T. L. (1998). Parental socialization of emotion. Psychological Inquiry, 9(4), 241-273.

Eyberg, S. M., Nelson, M. M., Duke, M., \& Boggs, S. R. (2005). Manual for the parent-child interaction coding system $\left(3^{\text {rd }}\right.$ ed.).

Eyberg, S. M., Nelson, M. M., Ginn, N. C., Bhuivan, N., \& Boggs, S. R. (2013). Dyadic parentchild interaction coding system: Comprehensive manual for research and training $\left(4^{\text {th }}\right.$ ed.).

Eyberg, S. M., \& Pincus, D. (1999). Eyberg Child Behavior Inventory and Sutter-Eyberg Behavior Inventory-Revised: Professional Manual. Odessa, FL: Psychological Assessment Resources.

Falk, A. E., \& Lee, S. S. (2012). Parenting behavior and conduct problems in children with and without attention-deficit/hyperactivity disorder (ADHD): Moderation by callousunemotional traits. Journal of Psychopathology and Behavioral Assessment, 34(2), 172 181.

Fernandez, M. A., Chase, R. M., Ingalls, C. A., \& Eyberg, S. M. (2006). The Abridged Workbook: Coder Training Manual for the Dyadic Parent-Child Interaction Coding System (3 $\left.{ }^{r d} e d.\right)$. Retrieved October, 2013 from http://pcit,phhp.ufl.edu

Fosco, G. M., \& Grych, J. H. (2012). Capturing the family context of emotion regulation: A family systems model comparison approach. Journal of Family Issues, 34(4), 557-578.

Fossum, S., Morch, W., Handegard, B. H., Drugli, M. B., \& Larsson, B. (2009). Parent training for young Norwegian children with ODD and CD problems: Predictors and mediators of treatment outcome. Scandinavian Journal of Psychology, 50(2), 173-181.

Friedlander, S., Weiss, D. S., \& Traylor, J. (1986). Assessing the influence of maternal 
depression on the validity of the Child Behavior Checklist. Journal of Abnormal Child Psychology, 14(1), 123-133.

Gaensbauer, T. J., \& Mrazek, D. (1981). Differences in the patterning of affective expression in infants. J. Am. Acad. Child Psychiatry, 20: 673-691.

Garner, P. W. (1995). Toddlers' emotion regulation behaviors: The roles of social context and family expressiveness. The Journal of Genetic Psychology: Research and Theory on Human Development, 156(4), 417-430.

Gratz, K. L., \& Roemer, L. (2004). Multidimensional assessment of emotion regulation and dysregulation: Development, factor structure, and initial validation of the Difficulties in Emotion Regulation Scale. Journal of Psychopathology and Behavioral Assessment, $26(1), 41-54$.

Gross, J. J., \& Levenson, R. W. (1997). Hiding feelings: The acute effects of inhibiting positive and negative emotions. Journal of Abnormal Psychology, 106, 95-103.

Henggeler, S. W., Borduin, C. M., \& Mann, B. J. (1987). Intrafamily agreement: Association with clinical status, social desirability, and observational rating. Journal of Applied Developmental Psychology, 8(1), 97-111.

Hourigan, S. E., Goodman, K. L., \& Southam-Gerow, M. A. (2011). Discrepancies in parents' and children's reports of child emotion regulation. Journal of Experimental Child Psychology, 110(2), 198-212.

Kazdin, A. E. (1998). Research design in clinical psychology. Boston: Allyn \& Bacon.

Kennedy, S. C., Kim, J. S., Tripodi, S. J., Brown, S. M., \& Gowdy, G. (2014). Does parent-child interaction therapy reduce future physical abuse?: A meta-analysis. Research on Social Work Practice, 1-30.

Kim-Spoon, J., Cicchetti, D., \& Rogosch, F. A. (2013). A longitudinal study of emotion 
regulation, emotion lability-negativity, and internalizing symptomatology in maltreated and nonmaltreated children. Child Development, 84(2), 512-527.

Koblinsky, S.A., Kuvalanka, K.A., \& Randolph, S.M. (2006). Social skills and behavior problems of urban, African American preschoolers: Role of parenting practices, family conflict, and maternal depression. American Journal of Orthopsychiatry, 76(4), 554-563.

Loyd, B.H., \& Abidin, R.B. (1985). Revision of the parenting stress index. Journal of Pediatric Psychology, 10, 169-177.

Macklem, G. L. (2008). Practitioner's guide to emotion regulation in school-aged children. New York: Springer.

Morris, A. S., Silk, J. S., Steinberg, L., Myers, S. S., \& Robinson, L. R. (2007). The role of the family context in the development of emotion regulation. Social Development, 16(2), 361-388.

Neumann, A., van Lier, P. A., Gratz, K. L., \& Koot, H. M. (2010). Multidimensional assessment of emotion regulation difficulties in adolescents using the Difficulties in Emotion Regulation Scale. Assessment, 17(1), 138-149.

Onchwari, G., \& Keengwe, J. (2011). Examining the relationship of children's behavior to emotion regulation ability. Early Childhood Education Journal, 39(4), 279-284.

Patterson, G. R., \& Capaldi, D. M. (1991). Antisocial parents: Unskilled and vulnerable. In Cowan, Philip A. (Ed.), Family transitions (pp. 195-218). Hillsdale, NJ: Lawrence Erlbaum Associates.

Patterson, G. R., Reid, J. B., \& Dishion, T. J. (1992). Antisocial boys. Eugene, OR: Castalia. Richerson, L. A. (2008). Behavioral, cognitive, and affective predictors of child conduct problems in the context of parent-child interactions. Dissertation Abstracts International: Section B: The Sciences and Engineering, 68(12-B), pp.8410.

Robinson, E. A., \& Eyberg, S. M. (1981). The Dyadic Parent-Child Interaction Coding System: 
Standardization and validation. Journal of Consulting and Clinical Psychology, 49, 245250.

Robinson, L. R., Morris, A. S., Heller, S. S., Scheeringa, M. S., Boris, N. W., \& Smyke, A. T. (2009). Relations between emotion regulation, parenting, and psychopathology in young maltreated children in out of home care. Journal of Child and Family Studies, 18(4), 421 434.

Rusch, S., Westermann, S., \& Lincoln, T. M. (2012). Specificity of emotion regulation deficits in social anxiety: An internet study. Psychology and Psychotherapy: Therapy, Research and Practice, 85(3), 268-277.

Seymour, K. E., Chronis-Tuscano, A., Halldorsdottir, T., Stupica, B., Ownes, K., \& Sacks, T. (2012). Emotion regulation mediates the relationship between ADHD and depressive symptoms in youth. Journal of Abnormal Child Psychology, 40(4), 595-606.

Shields, A., \& Cicchetti, D. (1997). Emotion regulation among school-age children: the development and validation of a new criterion q-sort scale. Developmental Psychology, 33, 906-916.

Shipman, K. L., Schneider, R., Fitzgerald, M. M., Sims, C., Swisher, L., \& Edwards, A. (2007). Maternal emotion socialization in maltreating and non-maltreating families: Implications for children's emotion regulation. Social Development, 16(2), 268-285.

Silk, J. S., Steinberg, L., \& Morris, A. S. (2003). Adolescents' emotion regulation in daily fife: Links to depressive symptoms and problem behavior. Child Development, 74(6), 18691880. doi: 10.1046/j.1467-8624.2003.00643.x

Stifter, C. A., \& Braungart, J. M. (1995). The regulation of negative reactivity in infancy: Function and development. Developmental Psychology, 31(3), 448-455.

Suveg, C., \& Zeman, J. (2004). Emotion regulation in children with anxiety disorders. Journal of Clinical Child and Adolescent Psychology, 33(4), 750-759. 
Thompson, R. A. (1994). Emotion regulation: A theme in search of definition. In N. A. Fox (Ed.), The development of emotion regulation: Biological and behavioral considerations, Monographs of the Society for Research in Child Development, 59(2/3), 25-52. Chicago, Ill.

Troy, A. S., \& Mauss, I. B. (2011). Resilience in the face of stress: Emotion regulation as a protective factor. In S. M. Southwich, B. T. Litz, D. Charney, \& M. J. Friedman (Eds.), Resilience and Mental Health: Challenges Across the Lifespan (30-44). Cambridge: Cambridge University Press.

Urquiza, A. J., \& McNeil, C. B. (1996). Parent-Child Interaction Therapy: An intensive dyadic intervention for physically abusive families. Child Maltreatment, 1(2), 134-144.

Volk-Stowell, R. T. (2006). Attention Deficit Hyperactivity Disorder (ADHD) and conduct problems: Attachment, emotion regulation and self-concept. Dissertation Abstracts International: Section B: The Sciences and Engineering, 66(7-B), 3962.

Wallace, N. M., Quetsch, L. B., Robinson, C., Gentzler, A. L., \& McNeil, C. B. (in press). Emotion regulation difficulties in caregivers and children: Transmission, influences, and implications for parent-training approaches. In M. A. Cyders (Ed.), Psychology of Impulsivity. NY: Nova Publishers.

Walton, A., \& Flouri, E. (2010). Contextual risk, maternal parenting and adolescent externalizing behaviour problems: The role of emotion regulation. Child: Care, Health and Development, 36(2), 275-284.

Webster-Stratton, C. (1990). Stress: Apotential disruptor of parent perceptions and family interactions. Journal of Clinical Child Psychology, 19, 302-312.

Weis, R., Lovejoy, M. C., \& Lundahl, B. W. (2005). Factor structure and discriminative validity of the Eyberg Behavior Inventory with young children. Journal of Psychopathology and Behavioral Assessment, 27(4), 269-278. 
Whiteside-Mansell, L., Ayoub, C., McKelvey, L., Faldowski, R. A., Hart, A., \& Shears, J. (2007). Parenting stress of low-income parents of toddlers and preschoolers:

Psychometric properties of a short form of the Parenting Stress Index. Parenting: Science and Practice, 7(1), 27-56. 
Table 1

Demographic information for entire sample $(N=60)$

$$
M(S D) \text { or } N(\%)
$$

\section{Caregiver}

Sex

Female

Male

Ethnicity

Caucasian

Other

Marital status

Single parent

Dual parent

Household income

Education

Grade school

High School

College

Graduate school

$\mathrm{CPS}^{\dagger}$
$57(95 \%)$

$3(5 \%)$

$48(80 \%)$

$12(20 \%)$

$20(33.3 \%)$

$40(66.7 \%)$

$39,224.62(48,658.26)$

$6(10 \%)$

$24(40 \%)$

$23(38.3 \%)$

$7(11.7 \%)$

$11(18.3 \%)$

Child

Sex

Female

$17(28.3 \%)$

Male

$43(71.7 \%)$

Ethnicity

Caucasian

$44(73.3 \%)$

Other

$16(26.7 \%)$

Age

4.62 (1.69)

ECBI

Intensity

$131.78(52.01)$

Problem

13.77 (11.08)

Note . CPS $=$ Child Protective Services. $\mathrm{ECBI}=$ Eyberg Child Behavior Inventory.

$\dagger=$ Families involved as foster parents were excluded from the sample $(n=2)$. 
Table 2

Demographic variables broken down by clinical and comparison groups

\begin{tabular}{|c|c|c|c|c|}
\hline & Clinical $^{\mathrm{a}}$ & Comparisons $^{b}$ & & \\
\hline & $M(S D)$ or $N(\%)$ & $M(S D)$ or $N(\%)$ & $t$ & $p$ \\
\hline \multicolumn{5}{|l|}{ Caregiver } \\
\hline Sex & & & .35 & .73 \\
\hline Female & $32(94.1 \%)$ & $25(96.2 \%)$ & & \\
\hline Male & $2(5.9 \%)$ & $1(3.8 \%)$ & & \\
\hline Ethnicity & & & .77 & .44 \\
\hline Caucasian & $26(76.5 \%)$ & $22(84.6 \%)$ & & \\
\hline Other & $8(23.5 \%)$ & $4(15.4 \%)$ & & \\
\hline Marital status & & & .07 & .37 \\
\hline Single parent & $13(38.2 \%)$ & $7(26.9 \%)$ & & \\
\hline Dual parent & $21(61.8 \%)$ & $19(73.1 \%)$ & & \\
\hline Household income & $\begin{array}{c}36,860.50 \\
(58,854.32)\end{array}$ & $42,134.31(32,970.88)$ & -.41 & .69 \\
\hline Education & & & -1.59 & .12 \\
\hline Grade school & $5(14.7 \%)$ & $1(3.8 \%)$ & & \\
\hline High School & $16(47.1 \%)$ & $8(30.8 \%)$ & & \\
\hline College & $9(26.5 \%)$ & $14(53.8 \%)$ & & \\
\hline Graduate school & $4(11.8 \%)$ & $3(11.5 \%)$ & & \\
\hline CPS & $10(29.4 \%)$ & $1(3.8 \%)$ & -2.90 & .01 \\
\hline \multicolumn{5}{|l|}{ Child } \\
\hline Sex & & & .36 & .72 \\
\hline Female & $9(26.5 \%)$ & $8(30.8 \%)$ & & \\
\hline Male & $25(73.5 \%)$ & $18(69.2 \%)$ & & \\
\hline Ethnicity & & & 1.81 & .08 \\
\hline Caucasian & $22(64.7 \%)$ & $22(84.6 \%)$ & & \\
\hline Other & $12(35.3 \%)$ & $4(15.4 \%)$ & & \\
\hline Age & $4.68(1.36)$ & $4.54(2.06)$ & .30 & .77 \\
\hline \multicolumn{5}{|l|}{ ECBI } \\
\hline Intensity & $\begin{array}{c}168.44(33.86) \\
T=70-71\end{array}$ & $\begin{array}{c}83.85(25.53) \\
T=46\end{array}$ & 10.63 & $<.01$ \\
\hline Problem & $\begin{array}{c}21.79(7.09) \\
T=69\end{array}$ & $\begin{array}{c}3.27(4.61) \\
T=45\end{array}$ & 12.23 & $<.01$ \\
\hline
\end{tabular}


Note . CPS $=$ Child Protective Services .

${ }^{\mathrm{a}} n=34 .{ }^{\mathrm{b}} n=26$. 
Table 3

Dependent variables broken down by clinical and comparison groups

\begin{tabular}{|c|c|c|c|c|c|c|}
\hline & \multicolumn{2}{|l|}{ Clinical $^{\mathrm{a}}$} & \multicolumn{2}{|l|}{ Comparisons ${ }^{b}$} & \multirow[b]{2}{*}{$t$} & \multirow[b]{2}{*}{$p$} \\
\hline & $M(S D)$ & \%ile & $M(S D)$ & \%ile & & \\
\hline \multicolumn{7}{|l|}{ DERS } \\
\hline Nonaccept & $12.24(5.93)$ & & $11.15(4.92)$ & & .75 & .46 \\
\hline Goals & $13.79(5.03)$ & & $10.54(4.69)$ & & 2.56 & .01 \\
\hline Impulse & $11.03(4.77)$ & & $8.42(3.19)$ & & 2.53 & .01 \\
\hline Aware & $14.59(4.15)$ & & $14.77(4.15)$ & & -.17 & .87 \\
\hline Strategies & $16.03(6.94)$ & & $12.50(4.09)$ & & 2.46 & .02 \\
\hline Clarity & $9.50(3.16)$ & & $8.73(2.93)$ & & .96 & .34 \\
\hline Total & $\begin{array}{c}77.18 \\
(20.51)\end{array}$ & & $66.12(16.28)$ & & 2.26 & .03 \\
\hline \multicolumn{7}{|l|}{ ERC } \\
\hline Lability/Negativity & $40.26(7.88)$ & & $24.08(4.52)$ & & 10.02 & $<.01$ \\
\hline Emotion Regulation & $24.06(2.72)$ & & $27.46(3.02)$ & & -4.58 & $<.01$ \\
\hline Total & $2.56(.38)$ & & $3.40(.31)$ & & -9.14 & $<.01$ \\
\hline \multicolumn{7}{|l|}{ CBCL } \\
\hline Internalizing & $14.65(8.87)$ & & $6.35(5.78)$ & & 4.14 & $<.01$ \\
\hline Externalizing & $28.29(9.67)$ & & $8.42(6.79)$ & & 9.34 & $<.01$ \\
\hline \multicolumn{7}{|l|}{ PSI } \\
\hline Parental Distress & $32.35(9.51)$ & $80-85$ & $26.38(8.11)$ & $55-60$ & 2.56 & .01 \\
\hline Dysfunction & $25.53(7.86)$ & $80-85$ & $19.19(6.32)$ & $50-55$ & 3.36 & $<.01$ \\
\hline Difficult Child & $40.88(8.22)$ & $95-99$ & $23.81(7.82)$ & $35-40$ & 8.14 & $<.01$ \\
\hline Total Stress & $\begin{array}{c}98.76 \\
(21.96)\end{array}$ & $90-95$ & $69.00(19.24)$ & 50 & 5.48 & $<.01$ \\
\hline
\end{tabular}

Note . DERS = Difficulties in Emotion Regulation Scale; ERC = Emotion Regulation Checklist;

$\mathrm{CBCL}=$ Child Behavior Checklist PSI $=$ Parenting Stress Index.

${ }^{\mathrm{a}} n=34 \cdot{ }^{\mathrm{b}} n=26$. 
Table 4

Correlation matrix of all participants across main outcome variables

\begin{tabular}{|c|c|c|c|c|c|c|c|c|c|}
\hline & $\begin{array}{c}\text { DERS } \\
\text { total }\end{array}$ & ERC total & CBCL Int & CBCL Ext & PSI total & $\begin{array}{c}\text { DPICS } \\
\text { Neg Talk }\end{array}$ & $\begin{array}{c}\text { DPICS } \\
\text { Command }\end{array}$ & $\begin{array}{c}\text { DPICS Child } \\
\text { Disruptive } \\
\text { Beh }\end{array}$ & $\begin{array}{c}\text { DPICS } \\
\text { Compliance }\end{array}$ \\
\hline DERS total & -- & & & & & & & & \\
\hline ERC total & $-.38 * *$ & -- & & & & & & & \\
\hline CBCL Int & $.37 * *$ & $-.71 * *$ & -- & & & & & & \\
\hline CBCL Ext & $.39 * *$ & $-.88 * *$ & $.75^{* *}$ & -- & & & & & \\
\hline PSI total & $.63^{* *}$ & $-.74 * *$ & $.68 * *$ & $.74 * *$ & -- & & & & \\
\hline $\begin{array}{l}\text { DPICS Neg } \\
\text { Talk }\end{array}$ & $.37 * *$ & $-.37 * *$ & $.34 * *$ & $.31 *$ & $.46^{* *}$ & -- & & & \\
\hline $\begin{array}{l}\text { DPICS } \\
\text { Command }\end{array}$ & .10 & -.21 & $.28^{*}$ & $.26^{*}$ & $.26^{*}$ & $.51 * *$ & -- & & \\
\hline $\begin{array}{l}\text { DPICS } \\
\text { Child } \\
\text { Disruptive } \\
\text { Beh }\end{array}$ & .06 & $-.34 * *$ & .21 & $.36^{* *}$ & .15 & .24 & .14 & -- & \\
\hline $\begin{array}{l}\text { DPICS } \\
\text { Compliance }\end{array}$ & -.20 & .24 & -.24 & $-.38 * *$ & -.21 & -.25 & $-.36^{* *}$ & $-.28 *$ & -- \\
\hline
\end{tabular}

Note. Correlations for all families $(N=60)$ in the sample are presented below the diagonal. For all scales, higher scores are indicative of more extreme responding in the direction of the construct assessed. DERS $=$ Difficulties in Emotion Regulation Scale; ERC $=$ Emotion Regulation Checklist; CBCL = Child Behavior Checklist; Int = Internalizing; Ext = Externalizing; PSI = Parenting Stre ss 
Index; DPICS = Dyadic Parent-Child Interaction Coding System; Neg Talk = Negative Talk; Child Disruptive Beh = Child Disruptive Behavior.

$* p<.05, * * p<.01$ 
Table 5

Correlation matrix of all participants across selected demographic variables

\begin{tabular}{lccccccccc}
\hline & $\begin{array}{c}\text { DERS } \\
\text { total }\end{array}$ & $\begin{array}{c}\text { ERC } \\
\text { total }\end{array}$ & $\begin{array}{c}\text { CBCL } \\
\text { Int }\end{array}$ & $\begin{array}{c}\text { CBCL } \\
\text { Ext }\end{array}$ & $\begin{array}{c}\text { PSI } \\
\text { total }\end{array}$ & $\begin{array}{c}\text { DPICS } \\
\text { Neg Talk }\end{array}$ & $\begin{array}{c}\text { DPICS } \\
\text { Command }\end{array}$ & $\begin{array}{c}\text { DPICS Child } \\
\text { Disruptive Beh }\end{array}$ & $\begin{array}{c}\text { DPICS } \\
\text { Compliance }\end{array}$ \\
\cline { 2 - 9 } Income & -.12 & .17 & -.20 & -.20 & -.24 & -.21 & -.03 & .04 & .23 \\
Edc & -.18 & $.31 *$ & $-.33 *$ & $-.34 * *$ & -.25 & -.21 & -.12 & .01 & .09 \\
Child age & -.07 & -.06 & -.04 & -.19 & .03 & -.07 & $-.38 * *$ & -.15 & $.27 *$ \\
\hline
\end{tabular}

Note. Correlations for all families $(N=60)$ in the sample are presented. For all scales, higher scores are indicative of more extreme responding in the direction of the construct assessed. DERS $=$ Difficulties in Emotion Regulation Scale; ERC $=$ Emotion Regulation Checklist CBCL = Child Behavior Checklist Int = Internalizing; Ext = Externalizing; PSI = Parenting Stress Index; DPICS = Dyadic Parent-Child Interaction Coding System; Neg Talk = Negative Talk; Child Disruptive Beh = Child Disruptive Behavior; Edc = Education.

$* p<.05, * * p<.01$. 
Table 6

Linear regression predicting DERS total scores from significant predictors

\begin{tabular}{lcccc}
\hline & $\beta$ & $p$ & $R^{2}$ & Adjusted $R^{2}$ \\
\cline { 2 - 4 } Prediction model & & & & .37 \\
ERC total & .14 & .53 & .65 & \\
CBCL Int & -.04 & .83 & & \\
CBCL Ext & -.05 & .84 & \\
PSI total & .75 & $<.01$ & \\
DPICS Neg & .11 & .37 & \\
Talk & & & \\
\hline
\end{tabular}

Note . DERS $=$ Difficulties in Emotion Regulation Scale ERC $=$ Emotion Regulation Checklist;

$\mathrm{CBCL}=$ Child Behavior Checklist Int $=$ Internalizing; Ext $=$ Externalizing; PSI $=$ Parenting

Stress Index; DPICS = Dyadic Parent-Child Interaction Coding System; Neg Talk = Negative

Talk. 
Table 7

Linear regression predicting ERC total scores from significant predictors

\begin{tabular}{lcccc}
\hline & $\beta$ & $p$ & $R^{2}$ & Adjusted $R^{2}$ \\
\cline { 2 - 4 } Prediction model & & & & .77 \\
DERS total & .05 & .54 & .53 & \\
CBCL Int & -.06 & $<.01$ & \\
CBCL Ext & -.67 & .10 & \\
PSI total & -.20 & .48 & \\
DPICS Neg & -.05 & & \\
Talk & & .53 & \\
DPICS Child & -.05 & & \\
Disruptive Beh & & .89 & \\
Edc & .01 & & \\
\hline
\end{tabular}

Note. ERC = Emotion Regulation Checklist DERS = Difficulties in Emotion Regulation Scale;

$\mathrm{CBCL}=$ Child Behavior Checklist; Int $=$ Internalizing; Ext $=$ Externalizing; PSI $=$ Parenting

Stress Index; DPICS = Dyadic Parent-Child Interaction Coding System; Neg Talk = Negative

Talk; Child Disruptive Beh $=$ Child Disruptive Behavior; Edc $=$ Education. 
Table 8

Correlation matrix of clinical and nonclinical groups across main outcome variables

\begin{tabular}{|c|c|c|c|c|c|c|c|c|c|}
\hline & $\begin{array}{c}\text { DERS } \\
\text { total }\end{array}$ & ERC total & CBCL Int & CBCL Ext & PSI total & $\begin{array}{c}\text { DPICS } \\
\text { Neg Talk }\end{array}$ & $\begin{array}{c}\text { DPICS } \\
\text { Command }\end{array}$ & $\begin{array}{c}\text { DPICS Child } \\
\text { Disruptive } \\
\text { Beh }\end{array}$ & $\begin{array}{c}\text { DPICS } \\
\text { Compliance }\end{array}$ \\
\hline DERS total & -- & $-.39 *$ & $.41 *$ & .20 & $.53 * *$ & .10 & -.08 & .12 & -.09 \\
\hline ERC total & -.20 & -- & $-.70 * *$ & $-.62 * *$ & $-.58 * *$ & -.23 & -.10 & -.23 & -.08 \\
\hline CBCL Int & .23 & $-.57 * *$ & -- & $.67 * *$ & $.59 * *$ & .13 & .30 & .08 & -.17 \\
\hline CBCL Ext & .30 & $-.75 * *$ & $.67 * *$ & -- & $.51 * *$ & .06 & .37 & .10 & -.14 \\
\hline PSI total & $.63 * *$ & $-.55 * *$ & $.56 * *$ & $.59 * *$ & -- & .33 & .25 & -.18 & .10 \\
\hline $\begin{array}{l}\text { DPICS Neg } \\
\text { Talk }\end{array}$ & $.38 *$ & -.18 & .24 & .11 & $.37 *$ & -- & .35 & .10 & -.12 \\
\hline $\begin{array}{l}\text { DPICS } \\
\text { Command }\end{array}$ & .18 & $-.34 *$ & .28 & .31 & .29 & $.60 * *$ & -- & .26 & -.29 \\
\hline $\begin{array}{l}\text { DPICS } \\
\text { Child } \\
\text { Disruptive } \\
\text { Beh }\end{array}$ & -.03 & -.29 & .13 & .34 & .06 & .20 & .12 & -- & $-.39 *$ \\
\hline $\begin{array}{l}\text { DPICS } \\
\text { Compliance }\end{array}$ & -.18 & .18 & -.13 & $-.40 *$ & -.21 & -.23 & -.42 & -.25 & -- \\
\hline
\end{tabular}

Note. Correlations for clinical families $(n=34)$ are presented below the diagonal, and correlations for nonclinical comparison families $(n=26)$ are presented above the diagonal. For all scales, higher scores are indicative of more extreme responding in the direction of the construct assessed. DERS $=$ Difficulties in Emotion Regulation Scale; ERC $=$ Emotion Regulation Checklist; $\mathrm{CBCL}=\mathrm{Child}$ 
Behavior Checklist; Int = Internalizing; Ext = Externalizing; PSI = Parenting Stress Index; DPICS = Dyadic Parent-Child Interaction Coding System; Neg Talk = Negative Talk; Child Disruptive Beh = Child Disruptive Behavior.

$* p<.05, * * p<.01$ 
Table 9

Linear regression predicting DERS total scores from significant predictors by group

\begin{tabular}{|c|c|c|c|c|c|c|c|c|}
\hline & & \multicolumn{3}{|c|}{ Clinical } & \multicolumn{4}{|c|}{ Comparison } \\
\hline & $\beta$ & $p$ & $R^{2}$ & Adjusted $R^{2}$ & $\beta$ & $p$ & $R^{2}$ & $\begin{array}{c}\text { Adjusted } \\
R^{2}\end{array}$ \\
\hline \multicolumn{9}{|l|}{$\begin{array}{l}\text { Prediction } \\
\text { model }\end{array}$} \\
\hline ERC total & -.23 & .29 & .47 & .38 & -.15 & .60 & .34 & .18 \\
\hline CBCL Int & -.19 & .35 & & & .21 & .47 & & \\
\hline CBCL Ext & .18 & .47 & & & -.28 & .29 & & \\
\hline PSI total & .69 & $<.01$ & & & .51 & .05 & & \\
\hline DPICS & .19 & .21 & & & -.11 & .58 & & \\
\hline Neg Talk & & & & & & & & \\
\hline
\end{tabular}

Note . DERS $=$ Difficulties in Emotion Regulation Scale ERC = Emotion Regulation Checklist;

$\mathrm{CBCL}=$ Child Behavior Checklist; Int $=$ Internalizing; Ext $=$ Externalizing; PSI $=$ Parenting

Stress Index; DPICS = Dyadic Parent-Child Interaction Coding System; Neg Talk = Negative Talk. 
Table 10

Linear regression predicting ERC total scores from significant predictors by group

\begin{tabular}{|c|c|c|c|c|c|c|c|c|}
\hline & & \multicolumn{3}{|c|}{ Clinical } & \multicolumn{4}{|c|}{ Comparison } \\
\hline & $\beta$ & $p$ & $R^{2}$ & Adjusted $R^{2}$ & $\beta$ & $p$ & $R^{2}$ & $\begin{array}{c}\text { Adjusted } \\
R^{2}\end{array}$ \\
\hline \multicolumn{9}{|l|}{$\begin{array}{l}\text { Prediction } \\
\text { model }\end{array}$} \\
\hline DERS total & .17 & .33 & .60 & .50 & .00 & 1.0 & .62 & .48 \\
\hline CBCL Int & -.05 & .78 & & & -.36 & .12 & & \\
\hline CBCL Ext & -.60 & .01 & & & -.18 & .39 & & \\
\hline PSI total & -.24 & .25 & & & -.28 & .26 & & \\
\hline $\begin{array}{l}\text { DPICS Neg } \\
\text { Talk }\end{array}$ & -.07 & .67 & & & -.07 & .67 & & \\
\hline DPICS & -.05 & .75 & & & -.25 & .16 & & \\
\hline Child & & & & & & & & \\
\hline Disruptive & & & & & & & & \\
\hline Beh & & & & & & & & \\
\hline Edc & .01 & .96 & & & .11 & .49 & & \\
\hline
\end{tabular}

Note . ERC = Emotion Regulation Checklist DERS = Difficulties in Emotion Regulation Scale;

$\mathrm{CBCL}=$ Child Behavior Checklist Int $=$ Internalizing; Ext $=$ Externalizing; PSI $=$ Parenting

Stress Index; DPICS = Dyadic Parent-Child Interaction Coding System; Neg Talk = Negative

Talk; Child Disruptive Beh $=$ Child Disruptive Behavior; Edc $=$ Education. 
Table 11

Correlation matrix of all participants across DERS subscales and selected demographic variables

\begin{tabular}{lcccccccc}
\hline & $\begin{array}{c}\text { ERC } \\
\text { total }\end{array}$ & $\begin{array}{c}\text { CBCL } \\
\text { Int }\end{array}$ & $\begin{array}{c}\text { CBCL } \\
\text { Ext }\end{array}$ & $\begin{array}{c}\text { PSI } \\
\text { total }\end{array}$ & $\begin{array}{c}\text { DPICS } \\
\text { Neg Talk }\end{array}$ & $\begin{array}{c}\text { DPICS } \\
\text { Command }\end{array}$ & $\begin{array}{c}\text { DPICS Child } \\
\text { Disruptive Beh }\end{array}$ & $\begin{array}{c}\text { DPICS } \\
\text { Compliance }\end{array}$ \\
\cline { 2 - 8 } Nonaccept & & & & & & & & \\
Goals & -.10 & .16 & .17 & $.36 * *$ & $.29 *$ & .11 & -.04 & -.10 \\
Impulse & $-.37 * *$ & $.30 *$ & $.30 *$ & $.49 * *$ & .15 & .01 & .07 & -.07 \\
Aware & $-.44 * *$ & $.45 * *$ & $.46 * *$ & $.54 * *$ & $.39 * *$ & .07 & .06 & -.16 \\
Strategies & -.03 & .08 & .02 & .15 & -.27 & -.15 & .02 & -.07 \\
Clarity & -.10 & .14 & .16 & $.39 * *$ & $.26 *$ & .12 & .08 & -.24 \\
Total & $-.38 * *$ & $.37 * *$ & $.39 * *$ & $.63 * *$ & $.37 * *$ & .10 & .07 & -.20 \\
\hline
\end{tabular}

Note. Correlations for all families $(N=60)$ in the sample are presented. For all scales, higher scores are indicative of more extreme responding in the direction of the construct assessed. DERS = Difficulties in Emotion Regulation Scale; ERC = Emotion Regulation Checklist CBCL = Child Behavior Checklist Int = Internalizing; Ext = Externalizing; PSI = Parenting Stress Index; DPICS = Dyadic Parent-Child Interaction Coding System; Neg Talk = Negative Talk; Child Disruptive Beh = Child Disruptive Behavior; Edc $=$ Education.

$* p<.05, * * p<.01$. 
Table 12

Emotion regulation differences in the clinical sample of CPS and non-CPS referred families

\begin{tabular}{lccccc}
\hline & CPS $^{\mathrm{a}}$ & \multicolumn{2}{c}{ Clinical $^{\mathrm{b}}$} & & \\
& $M(S D)$ & $M(S D)$ & $t$ & $p$ & $d$ \\
\cline { 2 - 6 } & & & & & \\
\hline DERS total & $79.90(17.77)$ & $76.04(21.81)$ & .50 & .63 & .19 \\
ERC total & $2.38(.44)$ & $2.64(.34)$ & -1.87 & .07 & .66 \\
\hline
\end{tabular}

Note . CPS = Child Protective Services; DERS = Difficulties in Emotion Regulation Scale; ERC

$=$ Emotion Regulation Checklist.

${ }^{\mathrm{a}} n=10 .{ }^{\mathrm{b}} n=24$. 